\title{
SEISMIC ANALYSIS OF WATER TANK CONSIDERING EFFECT ON TIME PERIOD
}

\author{
Neha N. Walde ${ }^{1}$, Sakshi Manchalwar ${ }^{2}$, Amey Khedikar ${ }^{3}$ \\ ${ }^{I}$ Tulsiramji Gaikwad Patil College of engineering and technology, RTMNU, Nagpur University, \\ ${ }^{2}$ Asst Prof. Priyadarshini J L College of engineering, Nagpur \\ ${ }^{3}$ Asst Prof. Tulsiramji Gaikwad Patil College of engineering and technology, RTMNU, Nagpur University
}

\begin{abstract}
While comparing both IS 1893-1984 and IS 1893(part II), first section we consider effect of Seismic responses-base shear, base moment, direction of seismic force, effect of vertical ground acceleration, maximum hydrodynamic pressure, sloshing wave height and additional parameters which calculated using response spectra with change in staging height and performing a few simple calculations and graphs. Here we observe the effect on time period with reference to the staging height in same sample calculations and graph obtained for different quantity. And also collecting the actual site dimension's (parameters) situated in Nagpur, for evaluation effect of staging height on earthquake forces and effect of soil type conditions on earthquake forces with constant zone, analyzing the tank in SAP2000 for stiffness at different staging height. And analysis has been done by both IS codes. This analysis shows the difference between the all the parameters.
\end{abstract}

Keywords: IS 1893-1984, IS 1893(part II), SAP2000,

\section{INTRODUCTION}

Liquid containing tank are used to store the water and distribute it in peak periods. There are different types based on size, shape, material and porpose of use. Mainly used water tank are elevated and ground supported water tank. Now a days these tanks serves very important role in many ways like public and industrial use etc. these increase in use of tank are improve the importance of storage tanks.

Form engineer point of view storage tank should maintain sufficient strength and resist all the upcoming forces coming forward with safety. Because of that the forces in storage tank are studied and it is observe that the analysis of simple building and elevated storage tank are different due to their seismic and dynamic forces on tank, liquid inside the tank and hydrodynamic forces on the tank during earthquake. Behaviour of elevated storage tank during the earthquake there is need to understand their seismic behavior and formulate rotational and efficient method of their analysis of liquid storage tank with different staging height.

On design codes uses to evaluate seismic response of tanks. While using such an approach, various other parameters also get associated with the analysis. Some of these parameters are: Pressure distribution on tank wall due to lateral and vertical base excitation, time period of tank in lateral and vertical mode, effect of soil-structure interaction and maximum sloshing wave height. Design Codes have provisions with varying degree of details to suitably evaluate these parameters.

All results are tabulated and graphs were plotted among various parameters. Wherever significant relationship among different parameters were found the equations of these tends lines where verified with the observed parametric values.

\section{DETAILS EXPERIMENTAL}

For study the effect of different staging heights and different soil conditions following analysis is carried out by considering two water tanks with different staging heights and for two different zones. The analysis is carried out on reinforced cement concrete circular water tanks. Which are commonly used in practice. Grade of concrete and steel used are M25 and $\mathrm{Fe} 415$. In the analysis special moment resisting frame (SMRF) are considered. Elevated water tank having capacity $50 \mathrm{~m}^{3}$ and $250 \mathrm{~m}^{3}$ with staging height $12 \mathrm{~m}, 15 \mathrm{~m}$, $18 \mathrm{~m}, 21 \mathrm{~m}, 24 \mathrm{~m}$ and $27 \mathrm{~m}$. Considering $3 \mathrm{~m}$ height of each panel, Stiffness of staging for different heights is obtained by software SAP 2000. Medium soil sites and Soft soil sites are considered for analysis of water tank. With constant zone V.

Table-1: sizes of various component of water tank

\begin{tabular}{|l|l|l|}
\hline Capacity & $\mathbf{5 0 m}^{\mathbf{3}}$ & $\mathbf{2 5 0 \mathbf { m } ^ { \mathbf { 3 } }}$ \\
\hline Inner Dia. of container & $4.65 \mathrm{~m}$ & $10.15 \mathrm{~m}$ \\
\hline Depth of water in container & $3 \mathrm{~m}$ & $3.1 \mathrm{~m}$ \\
\hline Free board & $0.3 \mathrm{~m}$ & $0.3 \mathrm{~m}$ \\
\hline Roof slab & $0.12 \mathrm{~m}$ & $0.12 \mathrm{~m}$ \\
\hline Wall thickness & $0.2 \mathrm{~m}$ & $0.35 \mathrm{~m}$ \\
\hline Floor slab & $0.2 \mathrm{~m}$ & $0.25 \mathrm{~m}$ \\
\hline Floor beam & $0.25 \times 0.6 \mathrm{~m}$ & $0.5 \times 0.6 \mathrm{~m}$ \\
\hline Bracing & $0.3 \times 0.45 \mathrm{~m}$ & $0.3 \times 0.6 \mathrm{~m}$ \\
\hline Column & $4 \mathrm{Nos} .-$ & $9 \mathrm{Nos} .-$ \\
& $0.45 \mathrm{~m}$ Dia & $0.65 \mathrm{~m}$ Dia \\
\hline Depth of footing below GL & $2 \mathrm{~m}$ & $3.5 \mathrm{~m}$ \\
\hline $\begin{array}{l}\text { C/C distance between } \\
\text { column }\end{array}$ & $3.5 \mathrm{~m}$ & $3.5 \mathrm{~m}$ \\
\hline Gallery & $0.11 \mathrm{~m}$ & $0.11 \mathrm{~m}$ \\
\hline Gallery outer Dia & $7.05 \mathrm{~m}$ & $12.85 \mathrm{~m}$ \\
\hline C.G od empty container & $1.18 \mathrm{~m}$ & $1.196 \mathrm{~m}$ \\
\hline
\end{tabular}


Table-2: Stiffness of staging for different heights,

\begin{tabular}{|l|l|l|}
\hline \multicolumn{3}{|l|}{ Stiffness from SAP $2000 \mathrm{in} \mathrm{kN} / \mathrm{m}$} \\
\hline Height $(\mathrm{m})$ & $50 \mathrm{~m}^{3}$ & $250 \mathrm{~m}^{3}$ \\
\hline 12 & 22230.257 & 67680.93 \\
\hline 15 & 18809.005 & 57820.511 \\
\hline 18 & 16059.568 & 50131.52 \\
\hline 21 & 13953.781 & 44104.579 \\
\hline 24 & 13953.781 & 39492.029 \\
\hline 27 & 10932.947 & 35441.083 \\
\hline
\end{tabular}

\subsection{Time Period v/s Height}

Table-3: Impulsive time period for tank full for different soil conditions

\begin{tabular}{|c|c|c|c|c|}
\hline & & \multicolumn{2}{|c|}{ Impulsive time (sec) } & \\
\hline & \multicolumn{2}{|c|}{ Tank full/Medium soil } & \multicolumn{2}{|c|}{ Tank full/ Soft soil } \\
\hline $\begin{array}{l}\text { Height } \\
\text { (m) }\end{array}$ & $50 \mathrm{~m}^{3}$ & $250 \mathrm{~m}^{3}$ & $50 \mathrm{~m}^{3}$ & $250 \mathrm{~m}^{3}$ \\
\hline 12 & 0.415303 & 0.308415 & 0.415303 & 0.308415 \\
\hline 15 & 0.456530 & 0.341653 & 0.456530 & 0.341653 \\
\hline 18 & 0.504582 & 0.376673 & 0.504582 & 0.376673 \\
\hline 21 & 0.549681 & 0.407576 & 0.549681 & 0.407576 \\
\hline 24 & 0.594461 & 0.437995 & 0.594461 & 0.437996 \\
\hline 27 & 0.639471 & 0.467911 & 0.639471 & 0.467911 \\
\hline
\end{tabular}

Table-4: Convective time period for tank full for different soil conditions

\begin{tabular}{|c|c|c|c|c|}
\hline & & \multicolumn{2}{|c|}{ Convective time (sec) } & \\
\hline & \multicolumn{2}{|c|}{ Tank full/Medium soil } & \multicolumn{2}{|c|}{ Tank full/Soft soil } \\
\hline $\begin{array}{l}\text { Height } \\
(\mathrm{m})\end{array}$ & $50 \mathrm{~m}^{3}$ & $250 \mathrm{~m}^{3}$ & $50 \mathrm{~m}^{3}$ & $250 \mathrm{~m}^{3}$ \\
\hline 12 & 2.340835 & 3.661853 & 2.340835 & 3.6618539 \\
\hline 15 & 2.340835 & 3.661853 & 2.340835 & 3.6618539 \\
\hline 18 & 2.340835 & 3.661853 & 2.340835 & 3.6618539 \\
\hline 21 & 2.340835 & 3.661853 & 2.340835 & 3.6618539 \\
\hline 24 & 2.340835 & 3.661853 & 2.340835 & 3.6618539 \\
\hline 27 & 2.340835 & 3.661853 & 2.340835 & 3.6618539 \\
\hline
\end{tabular}

Table-5: Impulsive time period for Empty tank for different soil conditions

\begin{tabular}{|l|l|l|l|l|}
\hline & \multicolumn{4}{|c|}{ Impulsive time (sec) } \\
\hline & $\begin{array}{l}\text { Empty tank /Medium } \\
\text { soil }\end{array}$ & \multicolumn{2}{|l|}{ Empty tank /Soft soil } \\
\hline $\begin{array}{l}\text { Height } \\
(\mathrm{m})\end{array}$ & $50 \mathrm{~m}^{3}$ & $250 \mathrm{~m}^{3}$ & $50 \mathrm{~m}^{3}$ & $250 \mathrm{~m}^{3}$ \\
\hline 12 & 0.337223 & 0.258772 & 0.337223 & 0.258772 \\
\hline 15 & 0.372634 & 0.288791 & 0.372634 & 0.288791 \\
\hline 18 & 0.416256 & 0.320566 & 0.416256 & 0.320566 \\
\hline 21 & 0.456663 & 0.349048 & 0.456663 & 0.349048 \\
\hline 24 & 0.497103 & 0.377280 & 0.497103 & 0.377280 \\
\hline 27 & 0.538006 & 0.405222 & 0.538006 & 0.405222 \\
\hline
\end{tabular}

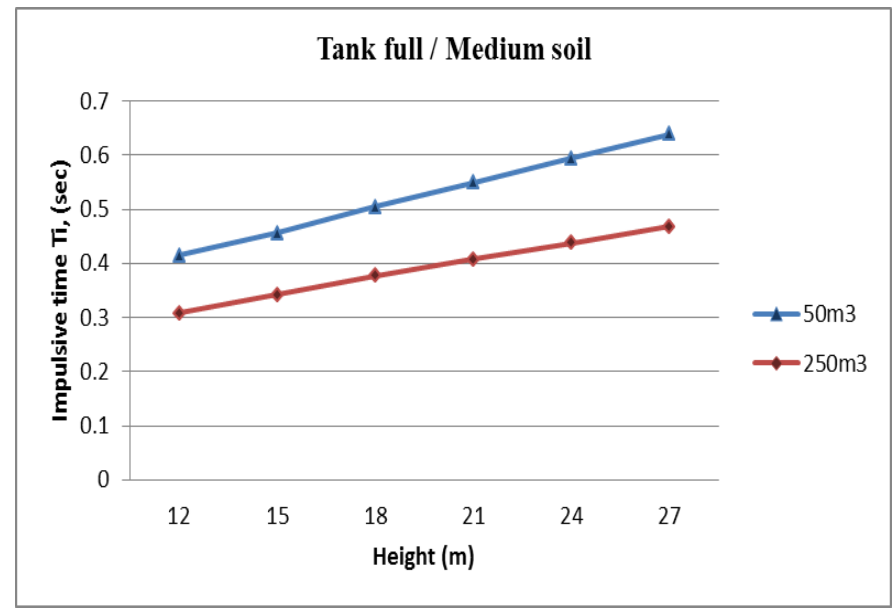

Fig-1: Impulsive time period for Full tank for Medium soil conditions

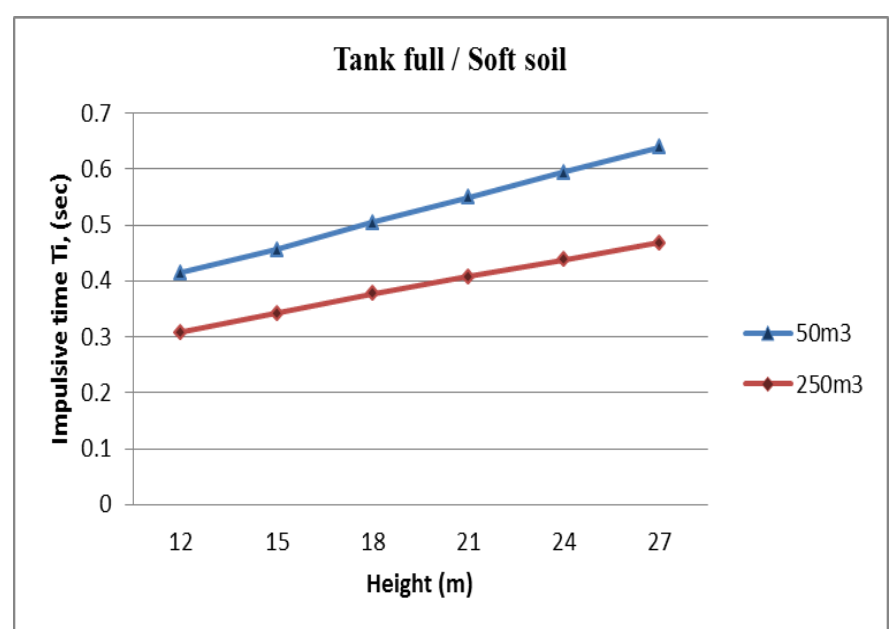

Fig-2: Impulsive time period for Full tank for Soft soil conditions

Fig 1 and Fig 2- Impulsive time period will not depend on type of soil sites. So that full tank $50 \mathrm{~m}^{3}$ and $250 \mathrm{~m}^{3}$ capacities has same values of impulsive time period for same staging height.

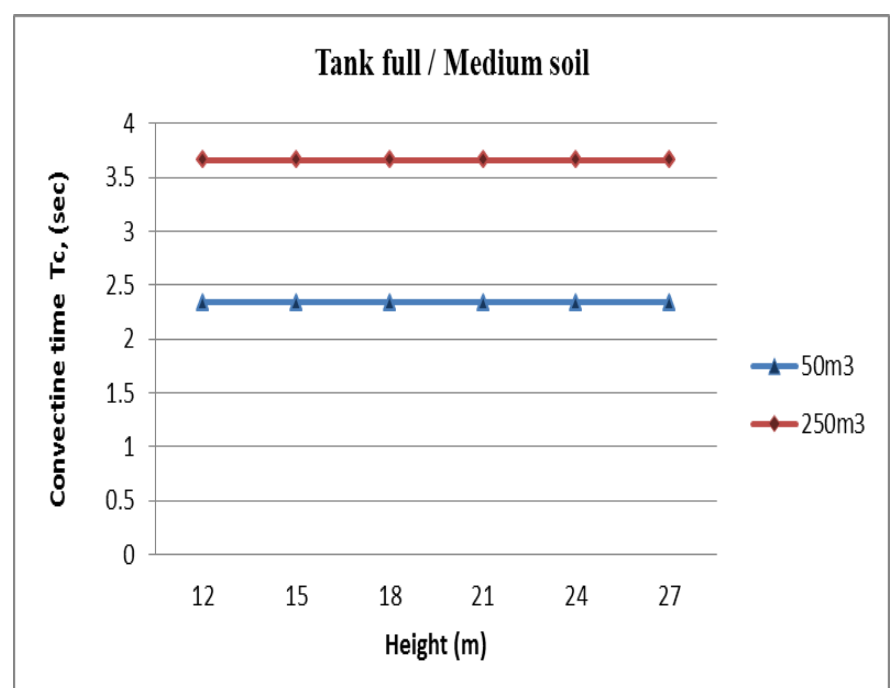

Fig-3: Convective time period for Full tank for Medium soil conditions 


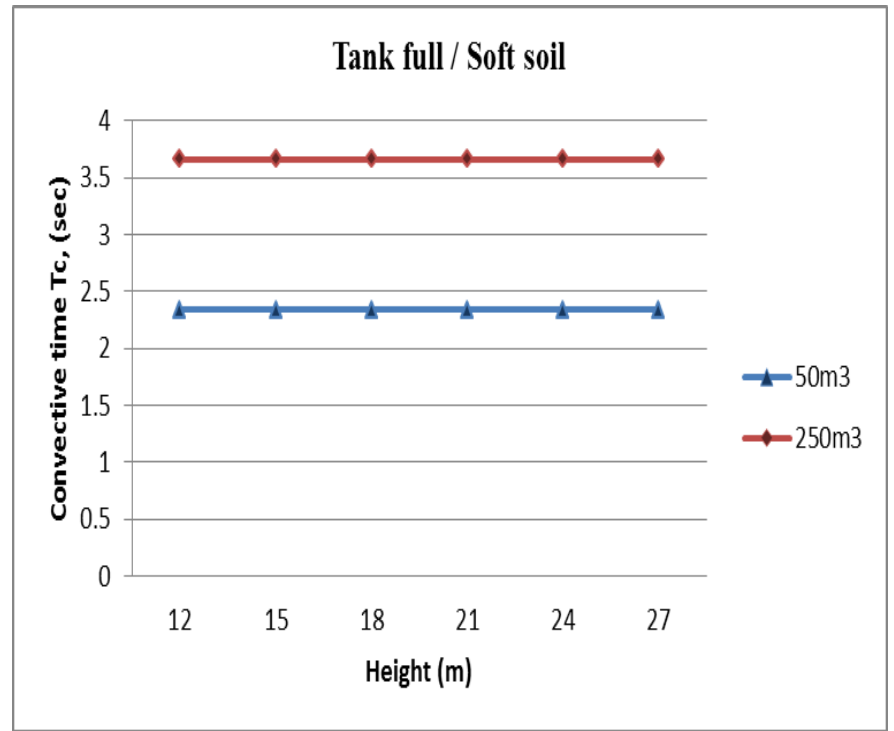

Fig-4: Convective time period for Full tank for Soft soil conditions

Fig. 3 and Fig.4- Convective time period also not depends on type of soil sites. In tank full condition $50 \mathrm{~m}^{3}$ and $250 \mathrm{~m}^{3}$ have constant value of Base shear because of convective time is depends on diameter of tank which is constant thought out increase staging height for both cases of water tank

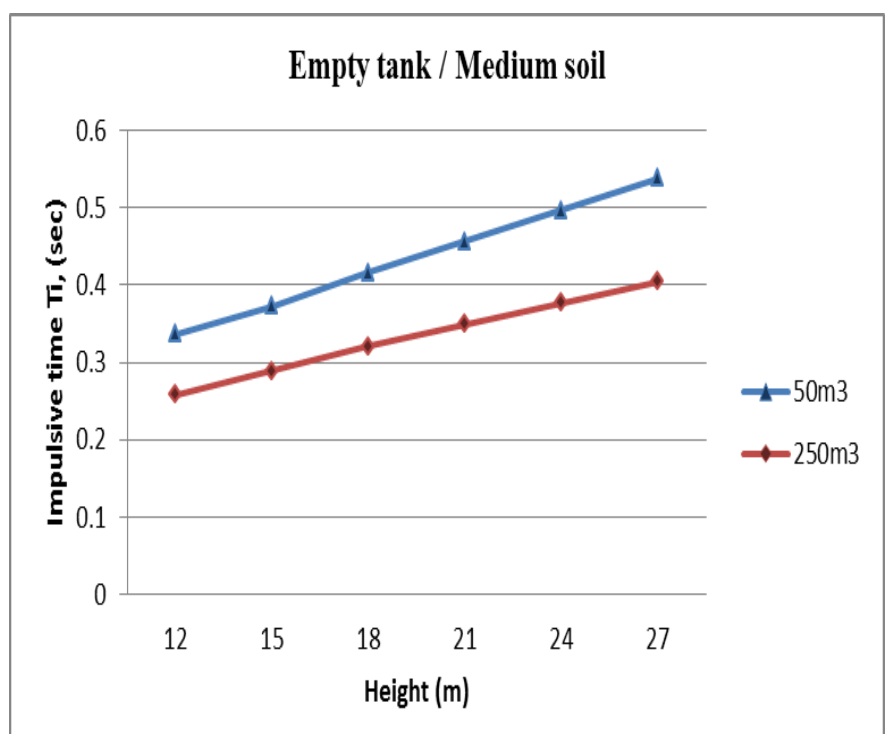

Fig-5: Impulsive time period for Medium soil for Empty tank conditions

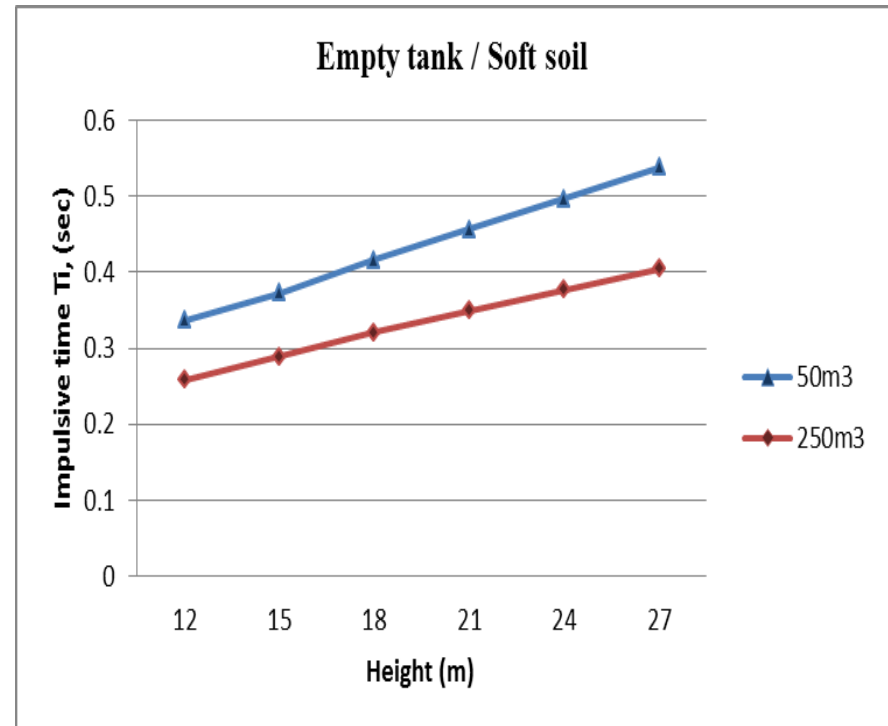

Fig-6: Impulsive time period for Soft soil for Empty tank conditions

Fig.5 and Fig.6- As we know Impulsive time period will not depend on type of soil sites. For Empty tank $50 \mathrm{~m}^{3}$ and $250 \mathrm{~m}^{3}$ capacities has same values of impulsive time period for same staging height

\section{RESULTS AND DISCUSSION}

Following data has been taken from actual site. Analysis has been done in SAP2000for evaluation stiffness and illustrate application of proposed revision and a comparison is also made between the results obtain by IS 1893-1984 and IS 1893(Part II) . and all the parameters has been observed.

EX 1- A RC circular water container of capacity 22.7 lack litter, has internal diameter $24.283 \mathrm{~m}$ and height of $5.6 \mathrm{~m}$ (including free board $0.3 \mathrm{~m}$ ). the tank is located on Nagpur region, having Zone II. Grade of concrete M25 and steel $\mathrm{Fe} 415$ is used and other details are given below.

Table-6: Design parameters

\begin{tabular}{|l|l|}
\hline Component & Size (mm) \\
\hline Roof Slab & 120 thick \\
\hline Wall & $\begin{array}{l}\text { Vertical wall } 310 \text { mm thick at bottom } \\
\text { upto } 2200 \text { mm than gradually reduced to } \\
\text { upto top }\end{array}$ \\
\hline Floor Slab & 285 thick \\
\hline Floor beam & 250 x 900 \\
\hline Gallery & 110 thick \\
\hline Roof Beams & $250 \times 350$ \\
\hline Braces & $250 \times 450$ \\
\hline Columns & 52 no. -600 dia. \\
\hline Inner container \\
\hline Column & $250 \times 250$ \\
\hline Braces & $250 \times 300$ \\
\hline
\end{tabular}




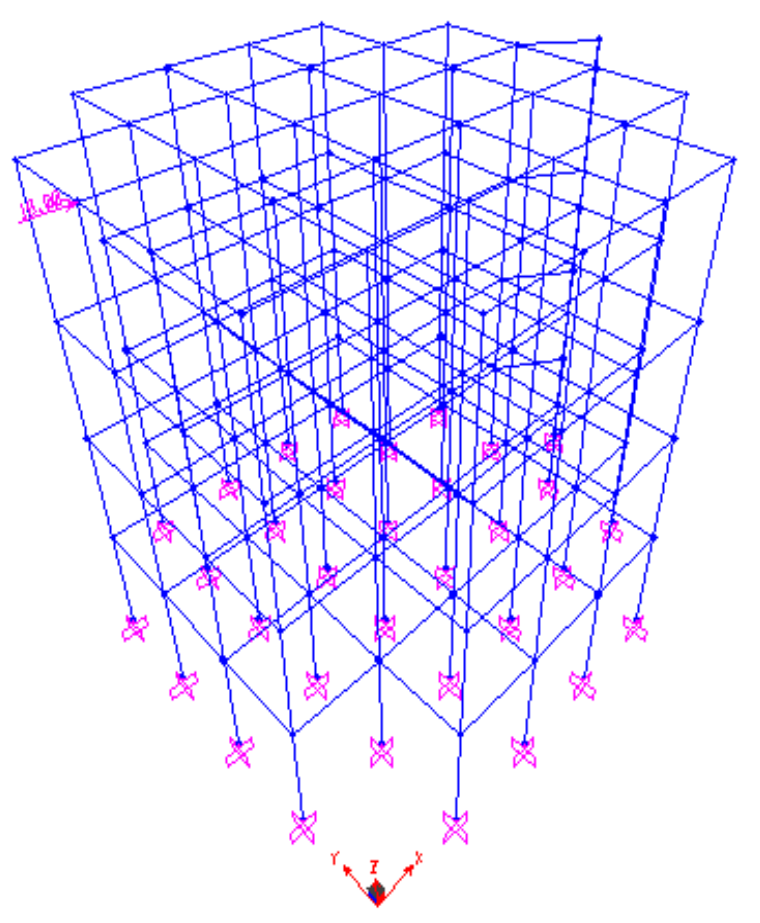

Fig-7: SAP model of staging

Here, analysis of staging is being performed for earthquake loading in X-direction. However, for some staging members this may not be the critical direction.

Here we cindering average stiffness and maximum stiffness both which observed by SAP2000.

Average stiffness $=32260.86 \mathrm{kN} / \mathrm{m}$

Maximum stiffness $=41322.31 \mathrm{kN} / \mathrm{m}$

Table-7: Comparison and Result obtained by IS 1893-1984 and IS 1893(Part II) Doc no 39 (7231) of Ex 1

\begin{tabular}{|c|c|c|c|}
\hline $\begin{array}{l}\text { Parameters of } \\
\text { tank }\end{array}$ & $\begin{array}{l}\text { IS 1893- } \\
1984\end{array}$ & IS 1893(Part I & \\
\hline $\begin{array}{l}\text { - Lateral } \\
\text { stiffness } \\
(\mathrm{kN} / \mathrm{m})\end{array}$ & $\begin{array}{ll}2.17 & \mathrm{x} \\
10^{6} & \end{array}$ & Avg $=32260.86$ & Max $=41322.31$ \\
\hline \multicolumn{4}{|c|}{ - $\quad$ Time period $(\mathrm{sec})$} \\
\hline $\begin{array}{l}\text { Impulsive } \\
\text { mode, Tank full } \\
\left(T_{i}\right) \\
\text { Tank Empty } \\
\left(T_{i}\right)\end{array}$ & $\begin{array}{l}0.253 \\
0.152\end{array}$ & $\begin{array}{l}1.45 \\
1.24\end{array}$ & $\begin{array}{l}1.28 \\
1.1\end{array}$ \\
\hline $\begin{array}{l}\text { Convective } \\
\text { mode, } \\
\text { Tank full }\left(T_{c}\right)\end{array}$ & & 6.61 & 6.61 \\
\hline \multicolumn{4}{|c|}{ - $\quad$ Design horizontal seismic coefficient } \\
\hline $\begin{array}{l}\text { Impulsive } \\
\text { mode, Tank full } \\
(A h)_{i} \\
\text { Tank Empty } \\
(A h)_{i}\end{array}$ & $\begin{array}{l}0.03 \\
0.03\end{array}$ & $\begin{array}{l}0.0345 \\
0.0402\end{array}$ & $\begin{array}{l}0.0387 \\
0.0455\end{array}$ \\
\hline $\begin{array}{l}\text { Convective } \\
\text { mode, Tank full } \\
A h)_{c}\end{array}$ & & 0.0132 & 0.0132 \\
\hline
\end{tabular}

\begin{tabular}{|l|l|l|l|}
\hline$\bullet$ & \multicolumn{4}{|l|}{ Base shear $V,(\mathrm{kN})$} \\
\hline Tank full & 1003.30 & 623.77 & 691.59 \\
\hline Tank Empty & 375.65 & 503.20 & 569.54 \\
\hline$\bullet$ & \multicolumn{4}{|l|}{ Overturningmoment } & $M,(\mathrm{kN}-\mathrm{m})$ \\
\hline Tank full & 21918.52 & 16773.32 & 18369.62 \\
\hline Tank Empty & 7888.74 & 12781.43 & 14466.54 \\
\hline
\end{tabular}

\section{CONCLUSION}

- $\quad$ From the above result it is clear that time period is increasing as the height increase thus it is concluded that earthquake forces decreases with increase in staging height because as staging height increases, the structure become more flexible. Therefore time period increases due to which Base shear decreases from lower to higher staging height. This affects the Earthquake forces

- Impulsive time period will not depend on type of soil sites. And for different capacity of tank, impulsive time is same for tank full condition.

- $\quad$ Convective time period also not depends on type of soil sites. In tank full condition different capacity tanks have constant value of Base shear because of convective time is depends on diameter of tank which is constant thought out increase staging height for both cases of soil types.

- As impulsive time of tank is not depend on type of soil so for different capacity of tank impulsive time will be same for different soil conditions.

- Impulsive time will decreases with increase in stiffness, in both tank full and empty and convective time is same for both cases.

- $\quad$ Base shear for tank full condition will be increase with increase in stiffness, and tank in empty condition it will be decreases.

- $\quad$ Same as base shear, overturning moment for tank full condition will be increase with increase in stiffness, and tank in empty condition it will be decreases.

\section{REFERENCES}

[1] Jain, Sudhir K., Jaiswal, O. R., (2007) 'IITK-GSDMA Guidelines for Seismic Design of Liquid Storage Tanks Provisions with commentary and explanatory examples'. Indian Institute of Technology Kanpur.

[2] Draft IS: 1893 (Part-II, Liquid Retaining Tanks) Criteria for Earthquake Resistant Design of Structures, Bureau of Indian standards, New Delhi, India.

[3] Waghmare, Pravin B., Raghatate, Atul M., \& Baraiya, Niraj D., (2012) "Comparative Performance of Elevated Isolated Liquid Storage Tanks (With Shaft Staging)" International Journal of Advanced Technology In Civil Engineering, ISSN: 2231 -5721, Volume-1, Issue2.

[4] IS 1893-1984-Part II, "Criteria for earthquake resistant design of structures" Bureau of Indian standards, new Delhi. 
[5] Jaiswal, O. R., Rai, Durgesh C., Jain, Sudhir K., (IITK-GSDMA) "IITK-GSDMA Guidline for seismic design of liquid storage tanks. Provisions with Commentary and Explanatory Examples".

[6] Martino, Giuseppe De, Giugni, Maurizio (1998) "Earthquake response of elevated storage tanks" Ein Dienst der ETH- Bibliothek Rämistrasse 101, 8092 Zürich, Schweiz. Prof Naples Univ Fedenco II Naples, Italy.

[7] Nicolae Zemtev, Amec Nuclear RO (2011) "Seismic analysis of vertical water tank ". SISOM 2011 and Session of the Commission of Acoustics, Bucharest 25-26 May.

[8] Ekbote, Pavan S., Kori, Jagadish G., (2013) "Seismic Behavior of RC Elevated Water Tankunder Different Types of Staging Pattern", Haveri, Karnataka, India. Journal of Engineering, Computers \& Applied Sciences (JEC\&AS) ISSN No: 2319-5606 Volume 2, No.8.

[9] Jabar, Ayazhussain M., Patel, H. S., (2012) "Seismic Behavior of RC Elevated Water Tank under different staging pattern and earthquake characteristics " M.E (CASAD), 2Associate Professor, Ahmadabad, Gujarat, India.International Journal of Advanced Engineering Research and Studies E-ISSN2249-8974 IJAERS/Vol. I/ Issue III/April-June, 2012/293-296.

[10] Shepherd, R., "The seismic response of elevated water tank supported on cross braced tower" associate professer of civil engg, university of auckland, new zealand.

[11] Bhattacharyya, Soumi., and Ghosh, Aparna (Dey)., (2012)“Seismic Vibration Control Of Elevated Water Tankes By Multiple Tuned Liquid Dampers". IIT Roorkee, Roorkee, Paper No. E009.

[12] lua, R. Livaog., angu nb, A. Dog., (2006) "Simplified seismic analysis procedures for elevated tanks considering fluid-structure-soil interaction" Turkey. Journal of Fluids and Structures 22 (2006) 421-439.

[13] Patel, Chirag N., Vaghela, Shashi N., Patel, H. S., (2012). "Sloshing Response of Elevated Water Tank Over Alternate Column Proportionality" International Journal of Advanced Engineering Technology EISSN 0976-3945IJAET/Vol.III/ Issue IV/Oct.-Dec., 2012/60-63.

[14] Jaiswal, O. R., Rai, Durgesh C., Meeri. AND Jain, Sudhir K., (2007) "Review of Seismic codes on liquid containing tanks". Earthquake spectra volume 23, no.1 pages 239-260, Earthquake Engineering Research Institute.

[15] Barbat, Horia., (1978) "The seismic analysis of elevated water tanks consiering the interaction phenomena", Politechnic institute of lasi, Civil Engineering Faculty, Structral Mechanics Department lasi, romania.

[16] Ching, ESE Tay Ah.,'Design and detailing of water retaining structure \& precast water tank floor system".

[17] Asari, Falhui P, Vanza, M. G., "Structural Control System For Elevated Water Tank" International Journal of Advanced Engineering Research and Studies E-ISSN2249-8974.
[18] Chen, J. Z., Ghemmaghami, A. R., and Kianoush, M. R., (2008) "Dynamic Analysis of Concrete Rectangular Liquid Storage Tank", the $14^{\text {th }}$ World Conference on Earthquake Engineering October 1217, Beijing, China.

[19] Ahmadi, Mohd. Taghi., Kalantari, Afshin., "Modling of Elevated water tank under Seismic Excitation considering Interaction of water and structure". 